\title{
Therapeutic monoclonal antibodies in oncology
}

\author{
Adam P Levene MB BSc ${ }^{1} \quad$ Guminder Singh BSc $^{2}$ Carlo Palmieri PhD MRCP ${ }^{3}$
}

J R Soc Med 2005;98:146-152

The mainstay of systemic therapy for solid and haematological malignancies in the 20th century was chemotherapy. This approach has the drawbacks of toxicity to normal tissue, drug resistance and lack of efficacy. The demand for more effective and tolerable treatments has led to the development of novel therapeutic agents that specifically target the malignant cell.

The hallmarks of malignant disease are self sufficiency in growth signals, insensitivity to growth inhibition, evasion of apoptosis, acquisition of limitless replicative potential, induction of angiogenesis and invasion and metastasis. ${ }^{1}$ All these processes are ultimately due to genetic defects which subsequently lead to the abrogation of normal cellular processes. Key to the development of targeted therapies is the ability to define the growth factors, transcription factors or receptors that phenotypically distinguish, in some way, the tumour from its normal counterpart. One class of novel agents that can specifically target and disrupt molecular pathways underlying tumorigenesis are the therapeutic monoclonal antibodies.

Monoclonal antibodies are produced by a single clone of B-cells, and are monospecific and homogeneous. Since the original report on production of such antibodies, by Kohler and Milstein ${ }^{2}$ in 1975, a vast number have become available. Early developments in the cancer sphere were made in the academic sector, with the identification of tumour-associated antigens and immunization with tumours to produce novel monoclonal antibodies. Initially, the antibodies were created by fusing B cells from immunized mice with human lymphoma cells, thus creating murine monoclonal antibodies. A big disadvantage of these preparations was that human recipients developed antimouse antibodies, which led to allergic reactions and reduced the efficacy. ${ }^{3}$ However, application of recombinant DNA technology led to the development first of chimeric antibodies, then of partially humanized antibodies, ${ }^{4,5}$ and ultimately of fully humanized antibodies. ${ }^{6}$ Box 1 outlines the features of the different types in this progression. Radiochemistry and antibody engineering research were initially driven by the

${ }^{1}$ Department of Cardiology, Leeds General Infirmary, Leeds LS1 3EX; ${ }^{2}$ Guy's, King's \& St Thomas' School of Medicine, Guy's Campus, London SE1 9RT; ${ }^{3}$ Department of Medical Oncology, Charing Cross Hospital, London W6 8RF, UK Correspondence to: Dr Carlo Palmieri, Department of Medical Oncology, Charing Cross Hospital, Fulham Palace Road, London W6 8RF, UK
Box 1 Types of monoclonal antibody that have been developed

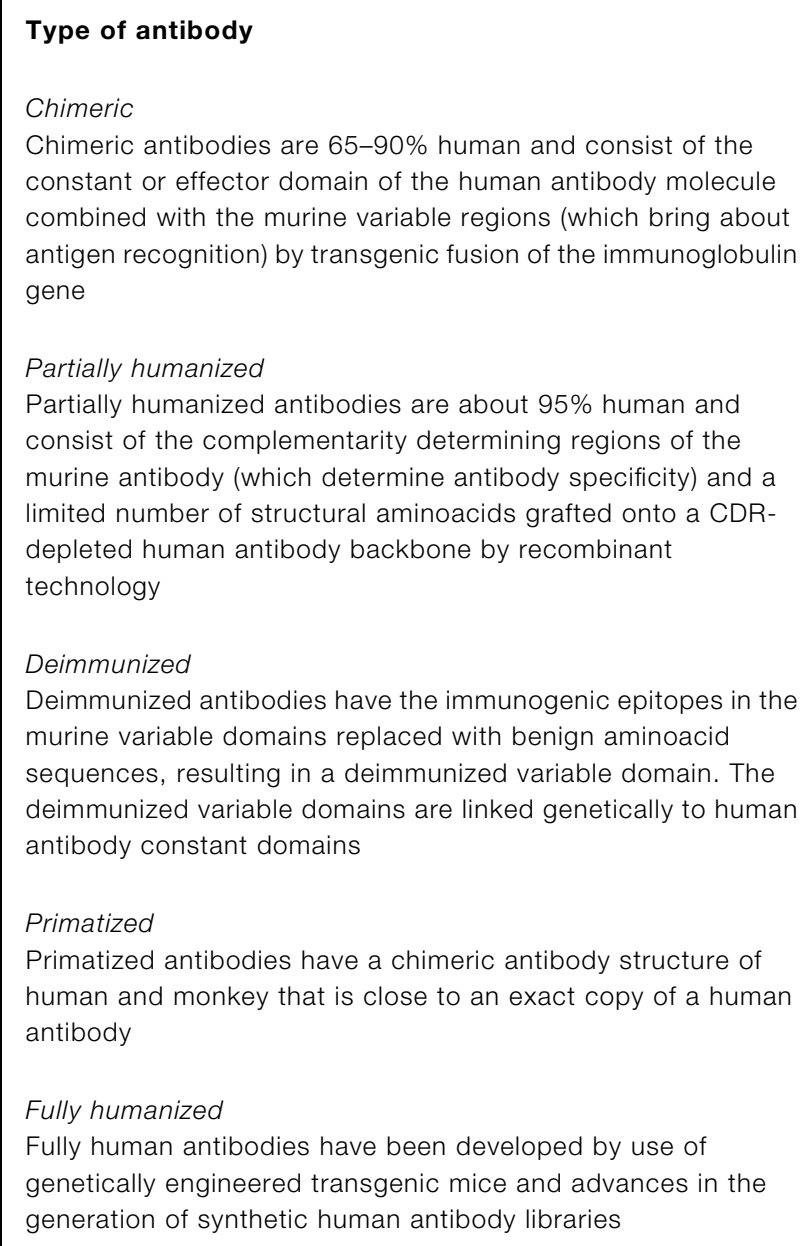

academic sector, followed by start-up biotech companies and subsequently larger pharmaceutical conglomerates. Whilst many of the antibodies were tested in the clinical setting - either unconjugated or more commonly as radioimmunoconjugates - very few (anti-CD20 being the first major exception) went on to be commercially developed.

At present, therapeutic monoclonal antibodies are being used in haematological and solid malignancies including non-Hodgkin's lymphoma, breast cancer and colorectal cancer. The mechanism of their antitumour effect is not precisely known but is thought to include complementdependent cytotoxicity, antibody-dependent cellular cytotoxicity and blocking or steric hindrance of the function of the target antigen. This review focuses on current use in 
oncology but Table 1 lists some of the antibodies in clinical development.

\section{RITUXIMAB}

\section{Low-grade non-Hodgkin's lymphoma}

Rituximab targets CD20, a cell surface protein present on healthy B-lymphocytes and on 95\% of B-cell lymphomas. It was the first therapeutic antitumour monoclonal antibody to be licensed in the USA (in 1997), the indication being treatment of recurrent or refractory low-grade B-cell lymphoma.

In the pivotal phase II trial, heavily pretreated patients with relapsed low-grade non-Hodgkin's lymphoma (NHL) were given single agent rituximab intravenously once a week for 4 weeks; $48 \%$ of patients responded, with a median response of 12 months. ${ }^{7}$ When previous responders were re-treated, $40 \%$ had a second response $(11 \%$ complete response, $30 \%$ partial response) with a median duration of response of 16.3 months (range 3.7 to 25.1 ). ${ }^{8}$ The antibody has also been found safe and effective when combined with standard-dose chemotherapy as first-line treatment: in a phase III trial in CD20 positive follicular NHL the response rate was $81 \%$ in the combination group (rituximab plus cyclophosphamide, vincristine and prednisolone) compared with $57 \%$ in the patients given chemotherapy alone $(P<0.001)$. Also, the median time to treatment failure was longer in the combination group -27 months versus 7 months, $P<0.001$. This benefit was not associated with a significant increase in toxic effects and represents an advance in the treatment of patients with follicular NHL. ${ }^{9}$

\section{High-grade non-Hodgkin's lymphoma}

The activity of rituximab in high-grade NHL was revealed in a randomized phase III study of cyclophosphamide, doxorubicin, vincristine and prednisolone (CHOP)

Table 1 A summary of monoclonal antibodies used in cancer medicine or in development

\begin{tabular}{|c|c|c|c|}
\hline Cancer & Target antigen & Monoclonal antibody (Ref) & Clinical status \\
\hline \multirow[t]{6}{*}{ Non-Hodgkin lymphoma } & CD20 & Rituximab (7-20) & In clinical use \\
\hline & & ${ }^{90} Y$-ibritumomab tiuxetan & In clinical use \\
\hline & & ${ }^{131}$ I-tositumomab & In clinical use \\
\hline & CD22 & Epratuzumab (56) & In clinical trials \\
\hline & & ${ }^{90} Y$-epratuzumab & In clinical trials \\
\hline & HLA-DR & Remitogen (57) & In clinical trials \\
\hline Acute myeloid leukaemia & CD33 & Gemtuzumab ozogamicin (52-55) & In clinical use \\
\hline $\begin{array}{l}\text { B-cell chronic lymphocytic } \\
\text { leukaemia }\end{array}$ & CD52 & Alemtuzumab (58) & In clinical use \\
\hline \multirow[t]{4}{*}{ Colorectal cancer } & Epidermal growth factor receptor (also & Cetuximab (26-35) & In clinical use \\
\hline & in trials in head and neck and non- & h-R3 (59) & In clinical trials \\
\hline & small-cell lung carcinoma) & ABX-EGF (60) & In clinical trials \\
\hline & A33 & huA33 (61) & In clinical trials \\
\hline Renal cell carcinoma & G250 & cG250 (62) & In clinical trials \\
\hline Melanoma & GD3 & KW-2189 (63) & In clinical trials \\
\hline Breast cancer & HER2 (C-erb2) & Trastuzumab (36-45) & In clinical use \\
\hline Prostate cancer & Prostate-specific membrane antigen & HuJ591 (64) & In clinical trials \\
\hline Small-cell lung cancer & CD56 & BB-10901 (65) & In clinical trials \\
\hline \multirow[t]{2}{*}{ Solid tumours } & $\begin{array}{l}\text { Vascular endothelial growth factor } \\
\quad \text { (VEGF) }\end{array}$ & Bevacizumab (47-51) & $\begin{array}{l}\text { In clinical use for metastatic } \\
\text { colorectal cancer and in clinical } \\
\text { trials in other tumour types }\end{array}$ \\
\hline & VEGF2 & IMC-1C11 (66) & In clinical trials \\
\hline \multirow[t]{2}{*}{ Epithelial cancers } & Carcinoembryonic antigen & ${ }^{90} \mathrm{Y}$-CEA-cide (67) & In clinical trials \\
\hline & Lewis $Y$ antigen & Hu3S193 (68) & In clinical trials \\
\hline
\end{tabular}


chemotherapy with or without rituximab in 399 previously untreated patients aged 60-80 years with stage II-IV diffuse large-B-cell lymphoma. ${ }^{10}$ At median follow-up of 3 years, the combination group had a higher event-free survival (53\% versus $35 \%, P=0.00008$ ) and better overall survival (62\% versus $51 \%, P=0.008)$, without an increase in toxicities. ${ }^{11}$ The clinical benefit in the combination arm seemed to depend on tumour expression of BCL2. ${ }^{12}$

The Mabthera International Trial (MinT study) was a phase III study which investigated patients aged 18-60 years and compared CHOP or similar chemotherapy plus rituximab with chemotherapy alone as first-line treatment for good-prognosis diffuse large-B-cell lymphoma. The study was closed early when an interim analysis showed a significantly longer time to treatment failure in the combination group. If the findings are borne out by further work, this combined strategy could mark a step forward in management of younger patients with this tumour.

Why should rituximab plus chemotherapy give better results than chemotherapy alone? One suggestion, emerging from in vitro studies, is that monoclonal antibodies sensitize lymphoma cells to the effects of chemotherapy. ${ }^{13,14}$

\section{Chronic lymphocytic leukaemia and small-cell lymphocytic leukaemia}

Response rates of $12 \%$ were initially reported in patients with previously treated small-cell lymphocytic leukaemia who were given rituximab; ${ }^{15}$ subsequently, however, better results were achieved with more frequent use of rituximab at standard doses and in dose-escalation studies. ${ }^{16,17}$ As first-line treatment in a phase II trial rituximab monotherapy gave a response rate of $51 \% .{ }^{18}$ In a further phase II trial by the Cancer and Leukemia Group B, rituximab plus fludarabine-based chemotherapy in previously untreated patients gave a higher response rate and more complete remissions than chemotherapy alone or the sequential use of rituximab after chemotherapy $(47 \%$ versus $28 \%$, $P=0.0049) .^{19}$

Rituximab is well tolerated. The most common sideeffects are infusion related and include fever, rigors, rash, bronchospasm and hypotension. Myelosuppression has also been reported.

\section{ANTI-CD20 MONOCLONAL ANTIBODIES CONJUGATED TO RADIOISOTOPES}

In the hope of improving their therapeutic efficacy, CD20 antibodies have been combined with yttrium and iodine as ${ }^{90}$ Y-ibritumomab tiuxetan and ${ }^{131}$ I-tositumomab. These molecules are administered as a single course treatment with the aim of eradicating not only the antibody-coated cells but also, by radiation, the antigen-negative cells in close proximity.

\section{${ }^{90} \mathrm{Y}$-ibritumomab tiuxetan}

${ }^{90}$ Y-ibritumomab tiuxetan consists of an anti-CD20 antibody that is covalently linked to MD-diethylenetriamine penta-acetic acid, allowing the binding of yttrium 90, a pure beta emitter. Multicentre studies of ${ }^{90} \mathrm{Y}$-ibritumomab tiuxetan for relapsed low-grade or intermediate-grade NHL have shown a response rate of $67 \%$ (26\% complete response), and median time to progression was more than 12.9 months. ${ }^{20}$ In follicular NHL that was refractory to rituximab treatment, $74 \%$ of patients responded (15\% complete response), with an estimated time to progression of 6.8 months. $^{21}$ In a phase III trial that compared ${ }^{90}$ Y-ibritumomab tiuxetan with rituximab in relapsed or refractory low-grade NHL, or transformed CD20-positive NHL with less than 25\% bone-marrow involvement, patients responded significantly better to ${ }^{90} \mathrm{Y}$-ibritumomab tiuxetan $(80 \%$ versus $56 \%, P=0.002$; complete response $30 \%$ versus $16 \%, P=0.04) .{ }^{22}$

\section{1|-tositumomab}

${ }^{131}$ I-tositumomab consists of an anti-CD20 antibody conjugated with iodine-131, a gamma emitter. Of patients with refractory low-grade or transformed low-grade lymphoma treated with ${ }^{131}$ I-tositumomab, 65\% responded (20\% complete response) with a median response duration of 6.5 months - results that compared favourably with patients' responses to their last chemotherapy. ${ }^{23}$ In untreated low-grade lymphoma a response rate of $100 \%$ (56\% complete response) has been reported with ${ }^{131} \mathrm{I}$ tositumomab. ${ }^{24}$ So far there has been no randomized trial directly comparing ${ }^{90}$ Y-ibritumomab tiuxetan with ${ }^{131} \mathrm{I}$ tositumomab.

The adverse effects associated with these radioisotopes include infusion-related reactions and myelosuppression with resultant neutropenic sepsis. Myelodysplasia and acute leukaemia have also been reported in treated patients, but interpretation is complicated by the fact that previous treatment has usually included alkylating agents. ${ }^{25}$

\section{CETUXIMAB}

Epidermal growth factor receptor (EGFR or HER1) is a tyrosine-kinase receptor and a member of the EGFR family. It is overexpressed in epithelial tumours such as lung, breast and colon, and its overexpression is associated with a poor prognosis. ${ }^{26-28}$ Cetuximab is a chimeric monoclonal antibody that binds to EGFR, blocking ligand binding and thus preventing receptor activation and downstream signalling.

Phase II trials have shown evidence of the activity of cetuximab, alone or in combination with irinotecan, in patients with EGFR-positive irinotecan-refractory metastatic colorectal cancer. ${ }^{29,31}$ A randomized controlled trial 
confirmed these results and suggested that re-treatment with cetuximab and irinotecan gave better results than cetuximab alone. The combination therapy group had a higher response rate $(22.9 \%$ versus $10.8 \%, P=0.007)$ and longer median time to progression (4.1 versus 1.5 months, $P<0.001)$. Median overall survival was also somewhat higher (8.6 months versus 6.9 months, $P=0.48$ ). ${ }^{31}$ On this evidence cetuximab has been licensed for use in the treatment of EGFR-positive metastatic colorectal cancer in combination with irinotecan for patients who are refractory to irinotecan. Studies on the use of cetuximab in head and neck, pancreatic and non-small-cell lung cancer have yielded promising results. ${ }^{32-35}$

The main adverse effect of cetuximab is an acne-like rash that occurs in up to $75 \%$ of patients. Development of this rash is a predictor of increased survival. ${ }^{35}$

\section{TRASTUZUMAB}

Trastuzumab is a humanized monoclonal antibody that targets HER2 (also known as C-erbB2), another member of the EGFR family. It is overexpressed in $30 \%$ of breast cancers and this overexpression in early-stage breast cancer is associated with adverse prognostic factors such as higher histological tumour grade, ${ }^{36}$ axillary lymph node involvement, ${ }^{37}$ increased mitotic rate, ${ }^{38}$ DNA ploidy, ${ }^{39}$ and lack of oestrogen and progesterone receptor expression; $;{ }^{40}$ it is also an independent adverse prognostic factor. ${ }^{41}$

In the pivotal phase III trial, patients with metastatic breast cancer overexpressing HER2 who had not previously received chemotherapy for metastatic disease were randomized to receive either standard chemotherapy alone or standard chemotherapy plus trastuzumab. Those who received trastuzumab plus chemotherapy had a longer median time to disease progression (7.4 months versus 4.6 months, $P<0.001$ ), a higher rate of objective response (50\% versus $32 \%, P<0.001)$, a longer median duration of response (9.1 months versus 6.1 months, $P<0.001$ ), longer median survival (25.1 months versus 20.3 months, $P=0.046$ ) and a $20 \%$ lower risk of death than patients who received chemotherapy alone. ${ }^{42}$ Those receiving combination treatment also had better gains in quality of life than those receiving chemotherapy alone. ${ }^{43}$ Currently this agent is licensed for the treatment of metastatic HER2-overexpressing breast cancer. Several randomized multicentre trials are now underway to investigate the benefits of adjuvant treatment with trastuzumab in HER2-positive primary breast cancer.

The main concern with trastuzumab is treatment-related cardiac dysfunction, ${ }^{44}$ which occurs with monotherapy but seems particularly troublesome with combined therapy in patients who have previously received anthracycline-based chemotherapy. The cardiac effects are probably explained by the expression of HER2 by cardiac myocytes, ${ }^{45}$ so cardiac function needs to be checked at baseline and monitored during treatment.

As with other monoclonal antibodies, trastuzumab in combination with chemotherapeutic agents has given higher response rates than either single agent alone. This has been particularly noteworthy with cisplatin, possibly because trastuzumab interferes with DNA repair induced by cisplatin and, as a result, promotes cytotoxicity in HER$2 /$ neu-overexpressing tumour target cells in a synergistic fashion. This effect of trastuzumab, termed receptorenhanced chemosensitivity, is specific for HER-2/neuoverexpressing cells, having no effect on cells without overexpression. ${ }^{46}$

\section{BEVACIZUMAB}

Bevacizumab is a humanized murine monoclonal antibody that targets vascular endothelial growth factor-A (VEGF-A) isoform. VEGF is an important endothelial cell-specific mitogen that regulates vascular proliferation and permeability and functions as an antiapoptotic factor for newly formed blood vessels. ${ }^{47}$ This therapeutic antibody targets the process of angiogenesis and the acquisition of new blood vessels by a tumour - a key process if a tumour is to grow and metastasize.

A phase III study in metastatic colorectal cancer showed better results with bevacizumab plus chemotherapy than with chemotherapy alone in terms of response ( $45 \%$ versus $35 \%, P=0.0029)$, median progression-free survival (10.6 versus 6.2 months, $P<0.00001)$, and median overall survival (20.3 versus 15.6 months, $P=0.00003) .{ }^{48}$ In metastatic renal cell carcinoma high-dose bevacizumab has increased the time to progression compared with placebo. ${ }^{49}$ In a phase II study high-dose bevacizumab plus carboplatin and paclitaxel gave a higher response rate $(31.5 \%$ versus 18.8 ) and longer median time to progression (7.4 versus 4.2 months) than chemotherapy alone. ${ }^{50} \mathrm{~A}$ phase III trial in taxane-resistant metastatic breast cancer showed a better response rate with bevacizumab and capecitabine than with capecitabine alone $(19.8 \%$ versus $9.1 \%)$ but there was no difference in median time to progression. ${ }^{51}$

Adverse effects reported with bevacizumab have included grade 3 hypertension, proteinuria, gastrointestinal perforation, pulmonary haemorrhage, epistaxis and thrombosis.

\section{GEMTUZUMAB OZOGAMICIN}

Gemtuzumab ozogamicin is a combination of cytotoxic agent (calicheamicin) and anti-CD33 monoclonal antibody. CD33 is expressed on myeloid blasts in $80 \%$ of acute myeloid leukaemia as well as on maturing haemopoieticprogenitor cells but is not present on healthy stem cells. ${ }^{52}$ On binding to $\mathrm{CD} 33$, the molecule is internalized into the 
cell, and the active drug is subsequently released, resulting in cleavage of double-stranded DNA. ${ }^{53}$

In phase II studies in acute myeloid leukaemia at first relapse, $30 \%$ of patients achieved complete remission, with a median relapse-free survival for these patients of 7.2 months. ${ }^{54}$ Adverse effects include infusion reactions, thrombocytopenia, neutropenic sepsis and reversible hepatotoxicity. Currently this agent is indicated for patients with AML who are older than 60 years of age. ${ }^{55}$ Studies are underway on the effects of gemtuzumab ozogamicin in combination with chemotherapy for high-risk myelodysplastic syndromes and as first-line treatment of acute myeloid leukaemia.

\section{CONCLUSION}

The development of therapeutic monoclonal antibodies has already improved the outlook for a large number of patients. In most studies to date their efficacy seems greatest when they are combined with standard cytotoxic agents. The challenge now facing oncologists is to learn how to use these agents to their maximum benefit - the optimal timing with regard to chemotherapy, the optimal duration of use, what to do at disease progression, their value in the adjuvant setting and their value in combination with other novel agents such as tyrosine kinase inhibitors.

\section{REFERENCES}

1 Hanahan D, Weinberg RA. The hallmarks of cancer. Cell 2000; 100:57-70

2 Kohler G, Milstein C. Continuous cultures of fused cells secreting antibody of predefined specificity. Nature 1975;256:495-7

3 Reilly R, Sandhu J, Alvarez-Diez TM, et al. Problems of delivery of monoclonal antibodies: pharmaceutical and pharmacokinetic solutions. Clin Pharmacokinet 1995;28:126-42

4 Winter G, Harris WJ. Humanized antibodies. Immunol Today 1993; 14:243-6

5 Jones PT, Dear PH, Foote J, et al. Replacing the complementaritydetermining regions in a human antibody with those from a mouse. Nature 1986;321:522-5

6 Reff ME, Hariharan K, Braslawsky G. Future of monoclonal antibodies in the treatment of hematologic malignancies. Cancer Control 2002;9:152-66

7 McLaughlin P, Grillo-Lopez J, White C, et al. IDEC-C2B8 rituximab chimeric anti-CD20 monoclonal antibody therapy for relapsed indolent lymphoma: half of patients respond to a four-dose treatment program. J Clin Oncol 1998;16:2825-33

8 Davis T, Grillo-Lopez J, White C, et al. Rituximab anti-CD20 monoclonal antibody therapy in non-Hodgkin's lymphoma: safety and efficacy of retreatment. J Clin Oncol 2000;18:3135-43

9 Marcus R, Imrie K, Belch A, et al. An international multi-centre, randomised open-label phase III trial comparing rituximab added to CVP chemotherapy to CVP chemotherapy alone in untreated stage III/IV follicular non-Hodgkin's lymphoma. Blood 2003;102:Abstr 87

10 Coiffier B, Lepage E, Briere J, et al. CHOP chemotherapy plus rituximab compared with $\mathrm{CHOP}$ alone in elderly patients with diffuse large-B-cell lymphoma. N Engl J Med 2002;346:235-42
11 Coiffier B, Herbrecht R, Tilly H, et al. GELA study comparing CHOP and R-CHOP in elderly patients with DLCL: 3-year median follow-up with analysis according to co-morbidity factors. Proc Am Soc Clin Oncol 2003;22:596

12 Mounier N, Briere J, Gisselbrecht C, et al. Rituximab and CHOP (RCHOP) overcomes bcl2-associated resistance to chemotherapy in elderly patients with diffuse large B cell lymphoma (DLBCL). Blood 2003; 101:4279-84

13 Demidem A, Lam T, Alas S, et al. Chimeric anti-CD20 (IDECC2B8) monoclonal antibody sensitizes a B cell lymphoma cell line to cell killing by cytotoxic drugs. Cancer Biother Radiopharm 1997; 12:177-86

14 Johnson TA, Press OW. Synergistic cytotoxicity of iodine-131-antiCD20 antibodies and chemotherapy for treatment of B-cell lymphomas. Int J Cancer 2000;85:104-12

15 Rayzman V, Scott A. Monoclonal antibodies for cancer therapy. Cancer Forum 2002;26:104-8

16 Byrd J, Murphy T, Howard R, et al. Rituximab using a thrice weekly dosing schedule in B-cell chronic lymphocytic leukemia and small cell lymphocytic lymphoma demonstrated clinical activity and acceptable toxicity. J Clin Oncol 2001;19: 2153-64

17 O'Brien S, Kantarjian H, Thomas D, et al. Rituximab dose escalation trial in chronic lymphocytic leukemia. J Clin Oncol 2001; 19:2165-70

18 Hainsworth J, Litchy S, Barton J, et al. Single-agent rituximab as first-line and maintenance treatment for patients with chronic lymphocytic leukemia or small-cell lymphocytic lymphoma: a phase II trial of the Minnie Pearl Cancer Research Network. J Clin Oncol 2003;21:1746-51

19 Byrd J, Petersen B, Park K, et al. Concurrent rituximab and fludarabine has a higher complete response rate than sequential treatment in untreated chronic lymphocytic leukemia patients: results from CALGB 9712. Blood 2001;98:Abstr 772

20 Witzig T, White $\mathrm{C}$, Wiseman G, et al. Phase I/II trial of IDEC-Y2B8 radioimmunotherapy for treatment of relapsed or refractory CD20(+) B-cell non-Hodgkin's lymphoma. J Clin Oncol 1999; 17:3793-803

21 Witzig T, Flinn I, Gordon L, et al. Treatment with ibritumomab tiuxetan radioimmunotherapy in patients with rituximab refractory follicular NHL. J Clin Oncol 2002;20:3262-9

22 Witzig T, Gordon L, Cabanillas F, et al. Randomised control trial of Yttrium 90-labelled ibritumomab tiuxetan radioimmunotherapy versus rituximab immunotherapy for patients with relapsed or refractory lowgrade follicular or transformed B-cell non-Hodgkin's lymphoma. J Clin Oncol 2002;20:2453-63

23 Kaminski M, Zelenetz A, Press O, et al. Pivotal study of iodine 131 tositumomab for chemotherapy-refractory low-grade or transformed low-grade non-Hodgkin's lymphomas. J Clin Oncol 2001; 19:3918-28

24 Kaminski M, Estes J, Regan D, et al. Front-line treatment of advanced B-cell low-grade lymphoma with radiolabelled anti-B1 antibody: initial experience. Proc Am Soc Clin Oncol 1997;16:15a

25 Dillman R. Radiolabelled anti-CD20 monoclonal antibodies for the treatment of B-cell lymphoma. J Clin Oncol 2002;20: $3545-57$

26 Kim E, Khuri F, Herbst R. Epidermal growth-factor receptor biology (IMC-C225). Curr Opin Oncol 2001;13:506-13

27 Porebska I, Harlozinska A, Bojarowski T. Expression of the tyrosine kinase activity growth factor receptors (EGFR, ERBB2, ERBB3) in colorectal adenocarcinomas and adenomas. Tumor Biol 2000;21:105-15

28 Salomon DS, Brandt R, Ciardiello F, Normanno N. Epidermal growth factor-related peptides and their receptors in human malignancies. Crit Rev Oncol Haematol 1995;19:183-232 
29 Saltz L, Rubin MS, Hochster HS, et al. Cetuximab (IMC-C225) plus irinotecan (CPT-11) is active in CPT-11 refractory colorectal cancer that expresses epidermal growth factor receptor. Proc Am Soc Clin Oncol 2001;20:Abstr 3

30 Saltz LB, Meropol NJ, Loehrer PJ Sr, et al. Phase II trial of cetuximab in patients with refractory colorectal cancer that expresses the epidermal growth factor receptor. J Clin Oncol 2004; 22:1201-8

31 Cunningham D, Humblet Y, Sienas S, et al. Cetuximab monotherapy and cetuximab plus irinotecan in irinotecan refractory metastatic colorectal cancer. N Engl J Med 2004;351:337-45

32 Robert F, Esekiel M, Spencer S, et al. Phase I study of anti-epidermal growth-factor receptor cetuximab in combination with radiation therapy in patients with advanced head and neck cancer. J Clin Oncol 2001;19:3234-43

33 Abbruzzese J, Rosenberg A, Xiong Q, et al. Phase II study of antiepidermal growth factor receptor (EGFR) antibody cetuximab (IMCC225) in combination with gemcitabine in patients with advanced pancreatic cancer. Proc Am Soc Clin Oncol 2001;20:130a

34 Gatzemeier U, Rosell R, Ramlau R, et al. Cetuximab in combination with cisplatin/vinorelbine vs cisplatin/vinorelbine alone in the firstline treatment of patients with epidermal growth-factor receptor expressing advanced non-small-cell lung cancer. Proc Am Soc Clin Oncol 2003;22:Abstr 642

35 Saltz L, Kies M, Abbruzzese J, et al. The presence and intensity of the cetuximab-induced acne-like rash predicts increased survival in studies across multiple malignancies. Proc Am Soc Clin Oncol 2003;22:204

36 Berger MS, Locher GW, Saurer S, et al. Correlation of c-erbB-2 gene amplification and protein expression in human breast carcinoma with nodal status and nuclear grading. Cancer Res 1988; 48:1238-43

37 Slamon DJ, Godolphin W, Jones LA, et al. Studies of the HER-2/neu proto-oncogene in human breast and ovarian cancer. Science 1989;244:707-12

38 Borg A, Baldetorp B, Fernö M, et al. ERBB2 amplification in breast cancer with a high rate of proliferation. Oncogene 1991;6:137-43

39 Stål O, Carstensen JM, Wingren S. Relationship of DNA ploidy and Sphase fraction to survival after first recurrence of breast cancer. Acta Oncol 1994;33:423-9

40 Quénel N, Wafflart J, Bonichon F. The prognostic value of c-erbB2 in primary breast carcinomas: a study on 942 cases. Breast Cancer Res Treat 1995;35:283-91

41 Slamon DJ, Clark GM, Wong SG, et al. Human breast cancer: correlation of relapse and survival with amplification of the HER-2/ neu oncogene. Science 1987;385:177-81

42 Slamon DJ, Leyland-Jones B, Shak S, et al. Use of chemotherapy plus a monoclonal antibody against HER2 for metastatic breast cancer that overexpresses HER2. N Engl J Med 2001;344:783-92

43 Osaba D, Slamon D, Burchmore M, et al. Effects on quality of life of combined trastuzumab and chemotherapy in women with metastatic breast cancer. J Clin Oncol 2002;20:3106-13

44 Seidman A, Hudis C, Pierri M, et al. Cardiac dysfunction in the trastuzumab clinical-trial experience. J Clin Oncol 2002;20: 1215-21

45 Schneider JW, Chang AY, Rocco TP. Cardiotoxicity in signal transduction therapeutics: erbB2 antibodies and the heart. Semin Oncol 2001;28(suppl):18-26

46 Pegram MD, Slamon DJ. Combination therapy with trastuzumab (Herceptin) and cisplatin for chemoresistant metastatic breast cancer: evidence for receptor-enhanced chemosensitivity. Semin Oncol 1999;26:89-95

47 Rosen LS. Clinical experience with angiogenesis signaling inhibitors: focus on vascular endothelial growth factor (VEGF) blockers. Cancer Control 2002;9(suppl):36-44
48 Hurwitz H, Fehrenbacher L, Cartwright T, et al. Bevacizumab a monoclonal antibody to vascular-endothelial growth factor prolongs survival in first-line colorectal cancer: results of a phase III trial of bevacizumab in combination with bolus IFL (irinotecan, 5 fluorouracil, leucovorin) as first-line therapy in subjects with metastatic colorectal cancer. Proc Am Soc Clin Oncol 2003;22:Abstr 3646

49 Yang JC, Haworth L, Sherry RM, et al. A randomised trial of bevacizumab, an anti-vascular-endothelial growth-factor antibody for metastatic renal cancer. N Engl J Med 2003;349:427-34

50 Johnson DH, Fehrenbacher L, Novotny WF, et al. Randomized phase II trial comparing bevacizumab plus carboplatin and paclitaxel with carboplatin and paclitaxel alone in previously untreated locally advanced or metastatic non-small-cell lung cancer. J Clin Oncol 2004;22:2184-91

51 Miller K, Rugo H, Cobleigh M, et al. Phase III trial of capecitabine plus bevacizumab versus capecitabine alone in women with metastatic breast cancer previously treated with anthracycline and a taxane. Breast Cancer Res Treat 2002;76(suppl):Abstr 36

52 Griffin J, Linch D, Sabbath K, et al. A monoclonal antibody reactive with normal and leukemic human myeloid progenitor cells. Leuk Res 1984;8:521-34

53 Schedinberg D, Lovett D, Divgi C, et al. A phase I trial of monoclonal antibody M195 in acute myelogenous leukemia: specific bone-marrow targeting and internalisation of radionuclide. J Clin Oncol 1991;9:47890

54 Sievers E, Larson R, Stadtmauer E, et al. Efficacy and safety of gemtuzumab ozogamicin in patients with CD33-positive acute myeloid leukemia in first relapse. J Clin Oncol 2001;19:3244-54

55 Bross PF, Beitz J, Chen G, et al. Approval summary: gemtuzumab ozogamicin in relapsed acute myeloid leukemia. Clin Cancer Res 2001; 7:1490-6

56 Furman RR, Coleman M, Leonard JP. Epratuzumab in non-Hodgkin's lymphomas. Curr Treat Options Oncol 2004;5:283-8

57 Stockmeyer B, Schiller M, Repp R, et al. Enhanced killing of B lymphoma cells by granulocyte colony-stimulating factor-primed effector cells and Hu1D10 - a humanized human leucocyte antigen DR antibody. Br J Haematol 2002;118:959-67

58 Lundin J, Kimby E, Bjorkholm M, et al. Phase II trial of subcutaneous anti-CD52 monoclonal antibody alemtuzumab (campath-1H) as firstline treatment for patients with B-cell chronic lymphocytic leukemia. Blood 2002;100:768-73

59 Vallis KA, Reilly RM, Chen P, et al. A phase I study of $99 \mathrm{mTc}-\mathrm{hR} 3$ (DiaCIM), a humanized immunoconjugate directed towards the epidermal growth factor receptor. Nucl Med Commun 2002;23:1155-64

60 Sridhar SS, Seymour L, Shepherd FA. Inhibitors of epidermal-growthfactor receptors: a review of clinical research with a focus on nonsmall-cell lung cancer. Lancet Oncol 2003;4:397-406

61 Welt S, Ritter G, Williams CJ, et al. Preliminary report of a phase I study of combination chemotherapy and humanized A33 antibody immunotherapy in patients with advanced colorectal cancer. Clin Cancer Res 2003;9:1347-53

62 Huland E, Heinzer H. Renal cell carcinoma: novel treatments for advanced disease. Curr Opin Urol 2003;13:451-6

63 Markovic SN, Suman VJ, Vukov AM, et al. Phase II trial of KW2189 in patients with advanced malignant melanoma. Am J Clin Oncol 2002; 25:308-12

64 Nanus DM, Milowsky MI, Kostakoglu L, et al. Clinical use of monoclonal antibody HuJ591 therapy: targeting prostate specific membrane antigen. J Urol 2003;170:S84-9

65 Murray N, Salgia R, Fossella FV. Targeted molecules in small cell lung cancer. Semin Oncol 2004;31:106-11

66 Posey JA, Ng TC, Yang B, et al. A phase I study of anti-kinase insert domain-containing receptor antibody, IMC-1C11, in patients with liver metastases from colorectal carcinoma. Clin Cancer Res 2003;9:1323-32 
67 Wong JYC, Chu DZ, Yamauchi DM, et al. A phase I radioimmunotherapy trial evaluating 90-yttrium-labelled anticarcinoembryonic antigen (CEA) chimeric T84.66 in patients with metastatic CEA-producing malignancies. Clin Cancer Res 2000;6:3855-63
68 Boghaert ER, Sridharan L, Armellino DC, et al. Antibody-targeted chemotherapy with the calicheamicin conjugate hu3S193-N-acetyl gamma calicheamicin dimethyl hydrazide targets Lewis $y$ and eliminates Lewis y-positive human carcinoma cells and xenografts. Clin Cancer Res 2004;10:4538-49 